\title{
Life cycle assessment of small-scale constructed wetland and extended aeration activated sludge wastewater treatment system
}

\author{
K. Lopsik
}

Received: 29 April 2012/Revised: 24 October 2012/ Accepted: 23 December 2012/Published online: 15 February 2013

(C) Islamic Azad University (IAU) 2013

\begin{abstract}
Wastewater treatment plants help to reduce negative impact on the environment by improving the quality of effluent. Different technologies are used in wastewater treatment, and one of the tasks is to find the most environmentally sound option, taking into account the use of resources and energy during construction and operation of the treatment system. The aim of the study is to assess environmental impacts from two different types of small-scale wastewater treatment systems, a constructed wetland and extended aeration activated sludge treatment system using Life Cycle Assessment method. The system boundaries include construction and operation phases. Assessment has been carried out using SimaPro software and Impact 2002+ and ReCiPe assessment methods with characterisation and normalisation stages. The results show that the main negative impact of constructed wetland is caused by the construction phase and use of lightweight expanded clay aggregate to construct the hybrid filter. Impacts from extended aeration activated sludge treatment system are mainly caused from the use of electricity and the quality of the effluent, therefore, the use phase has a larger impact on the life cycle. Since a large amount of energy is used to produce lightweight expanded clay aggregate, the impact of 1 population equivalent of constructed wetland is larger than the impact of extended aeration activated sludge treatment system. Constructed wetland dominates in human toxicity, acidification, land use, ozone layer depletion and the use of non-renewable resources categories. Extended aeration activated sludge
\end{abstract}

K. Lopsik (ه)

Department of Environmental Protection, Tartu College,

Tallinn University of Technology, Tallinn, Estonia

e-mail: kristel.lopsik@gmail.com treatment system dominates in categories associated with eutrophication and ecotoxicity.

Keywords Sewage - Light expanded clay aggregate Environmental impact $\cdot$ Impact $2002+\cdot \mathrm{ReCiPe}$

\section{Introduction}

The goal of a wastewater treatment plant (WWTP) is to reduce the environmental impact caused by the sewage to the environment. At the same time, treatment plants have an impact on the environment themselves by consuming resources for construction and operation. The development of novel sewage sludge treatment technologies are needed with the aim of solving severe environmental problems (Lillenberg et al. 2010). One way of analysing the impact from WWTPs from a holistic perspective is to use a method called Life Cycle Assessment (LCA), which is being widely used to compare technologies and constantly developed as a method. It is regulated with ISO 14040:2006 (2006) standard. LCA is a method used for compiling and evaluating inputs, outputs and potential environmental impacts of a product or service throughout its whole life cycle. LCA enables to assess the performance of a studied system or a product in a complex way, and gives a possibility to quantitatively assess impacts and to determine the aspects which influence the environmental performance most. However, LCAs like other system analysis tools in general are a simplification of the complex reality; there are several limitations in LCA, such as limitation in predicting future, understanding the processes and being site-specific (Moora 2009). The feature of LCA is that it predicts potential rather than actual impacts on the environment (Stewart et al. 1999). Limitations might rise 
from the chosen methodology, assumptions and impact coverage (ILCD Handbook 2010). LCAs are data intensive, they require a lot of high quality data; key issues are spatial boundaries, time scale over which life cycle comparison is made, scale at which comparison is made and the level of detail that the study goes into (Dixon et al. 2003). Renou et al. (2008) looked into the influence of the selected impact assessment method on the LCA outcome in the case of wastewater treatment and found that there is no effect of the assessment method used on greenhouse effect, resource depletion, eutrophication and acidification, but the results of toxicity differ. The system boundaries including the quality of data, made assumptions and chosen impact assessment methods should be explained and considered when carrying out LCA and interpreting results.

Most of Estonian WWTPs are designed for small-scale use. In year 2000, almost $96 \%$ of the total number of WWTPs in Estonia were constructed for a pollution load under 2000 population equivalent (p.e.) (EWC Ltd. 2002). $59 \%$ of WWTPs did not have discharge values as required by the Water Act, and therefore, these WWTPs need to be reconstructed to meet the requirements. Currently, most of the urgent problems are being solved or addressed and the challenge nowadays concerns wastewater treatment of communities located in rural areas (Nogueira et al. 2009). In larger municipalities efficient wastewater collection and treatment systems have been built. In rural areas or in some towns, on the other hand, there are systems which need to be reconstructed or to be re-built. This paper investigates two different types of WWTPs suitable for rural areas using LCA, to find an environmentally sound option in wastewater treatment.

The overall goal of wastewater treatment systems is to protect the environment from the load of nutrients and other compounds by complying with water quality parameters. According to Dixon et al. (2003), if minimisation of environmental impacts is one of the main functions of wastewater treatment systems, then they should be designed so that their total impact on the environment is reduced; the whole life cycle of the system must be considered. Water treatment technology which is based alone on technology to achieve high quality effluent may not reflect the most environmentally favourable option (Tangsubkul et al. 2005). LCA enables to analyse the whole impact of a treatment system to the environment. It helps to bring out aspects to minimise the impacts and develop the most favourable option on the whole.

According to Roeleveld et al. (1997), the first LCA of a WWTP was carried out on 1997. Larsen et al. (2007) estimates that according to scientific literature, about 20 WWTP LCAs have been carried out as of 2007. In total, about 30 different wastewater treatment technologies (2008b) and even more different types of scenarios, which involve combination of various stages of treatment and various technologies, have been assessed. These include the following scales: LCAs of water management, including drinking water, plumbing, sewerage, wastewater treatment (Lassaux et al. 2007; Tillman et al. 1998) and wastewater treatment, including building, use and demolition phases (Renou et al. 2008; Weiss et al. 2008), building or use phases of WWTPs (Del Broghi et al. 2008; Dixon et al. 2003; Foley et al. 2007; Lundin et al. 2000; Memon et al. 2007; Muñoz et al. 2006; Vlasopoulos et al. 2006) or use phase of WWTPs (Brix 1999; Gallego et al. 2008; Hospido et al. 2008).

In this paper, LCA of two WWTPs, a hybrid constructed wetland filter (CW) and extended aeration activated sludge treatment system (ASTS), has been carried out. Both systems are designed for pollution capacities under 2,000 p.e. The goal was to assess the environmental impacts from two different types of WWTPs using life cycle impact assessment methods, Impact 2002+ and ReCiPe. LCA software, SimaPro was used to assess the environmental impact from construction and operation phases. So far, LCA studies on CWs have been of systems using sand and gravel for filter material. This study analyses the use of a newer and more advanced material, lightweight expanded clay aggregate (LWA). Among some of the specifications of light expanded clay are lightness, moisture impermeability, incompressibility under permanent and steady pressure, non-decomposition and freezing and melting resistance (Malakootian et al. 2009). ASTS technology is one of the most feasible treatment systems in Estonia. Both treatment systems are located in Estonia, and the construction as well as the operation data has been gained from constructors, operators, previous research and local municipalities from period 2003-2010.

\section{Materials and methods}

\section{Description of studied WWTPs}

The objects under study are two different WWTPs: a hybrid CW used for a school sewage treatment and ASTS to treat sewage from a small municipality. Both of them are determined as small treatment systems designed for less than 2,000 p.e. For both the systems, the construction and operation phases were analysed, demolition phase was exempted. The study includes the impact from the release of treated water to the environment.

The CW treatment system has a calculated capacity of 64 p.e. WWTP consists of mechanical and biological treatment phases (Fig. 1). The raw wastewater goes through grease trap to a three-chamber septic tank, and is followed by a treatment in vertical and horizontal soil and 
Fig. 1 Process schema of constructed wetland
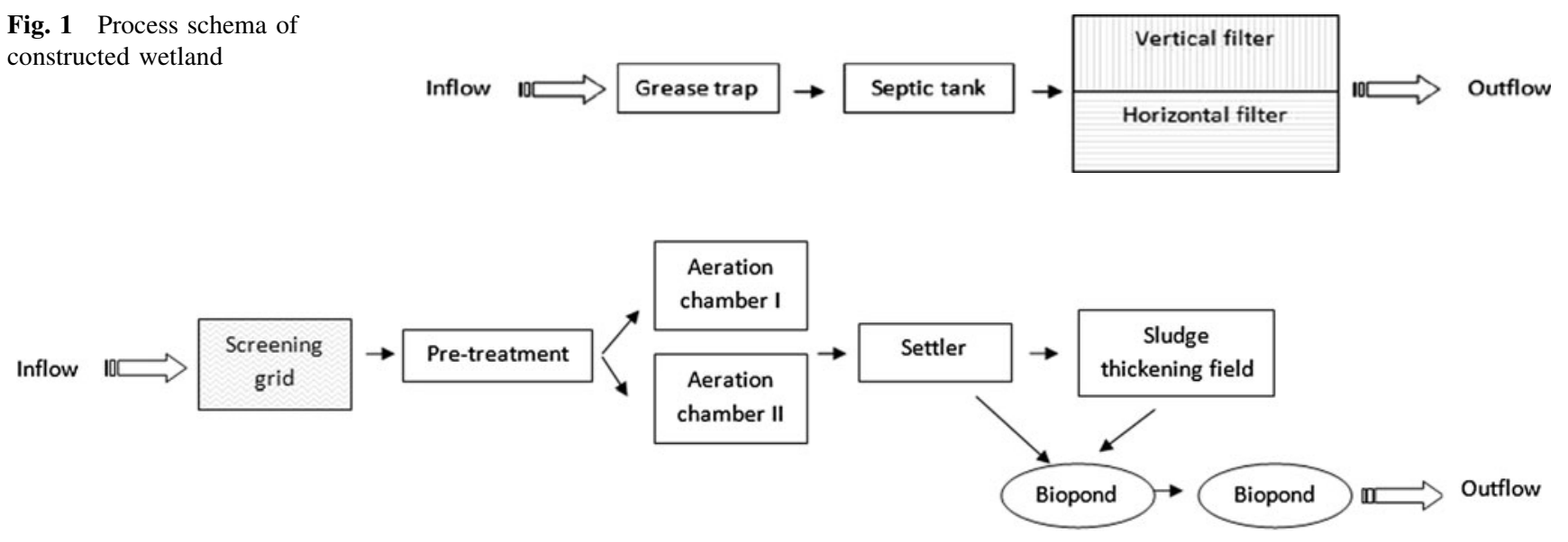

Fig. 2 Process schema of activated sludge treatment system

vegetation filter. The filling material used for the filter system is LWA and large-fractioned rubble.

The more conventional type of WWTP chosen for the case study is ASTS with a calculated capacity of 1,020 p.e. The system has mechanical, chemical and biological treatment phases with extended aeration (Fig. 2). Wastewater is directed through a screening grid following anaerobic phase, extended aeration aerobic chamber phase and settler. The pre-treated wastewater is discharged to bioponds for the last treatment before being discharged to the environment.

\section{LCA application}

According to definition, a short-internal LCA was carried out using SimaPro Faculty 7.2 version. Data were collected from previous research (Tooming 2005), construction projects and operators of WWTPs. Inventory data were connected with processes of SimaPro databases (Ecoinvent, ETH-ESU 96, IDEMAT 2001, Industry Data 2.0). The data which were selected from databases (e.g. production of plastic pipes, reinforced concrete, metals) had the following requirements: it was to represent a relatively new technology, data based on European industries and processes, data from the latest time possible (period 2003-2009). The data for the use of electricity in the operation phase were based on Estonian electricity profile which is dominated by the use of oil shale. The electricity data was gathered from the outcome of OSELCA project during which an LCA of oil shale produced electricity was carried out (Sabanov et al. 2006). This type of energy mix has not been used widely in LCAs, and the outcome is important for conducting local LCAs. In previous assessments of WWTP life cycle, mostly midpoint or endpoint assessment methods, such as Eco-Indicator 99, CML 2001, have been used. ILCD Handbook (2010) states that a newer approach is to integrate midpoint and endpoint impact categories. This study uses combined life cycle impact assessment methods, Impact 2002+ and $\mathrm{ReCiPe}$, which are relatively new and have not been used in WWTP LCAs. Two methods have been used to test the validity of the results.

System boundaries and functional unit

The current LCA has focused on the construction and operation phases of WWTPs (Fig. 3). Demolition phase has been exempted, since the impact when all waste is being recycled would be marginal compared to the rest of the systems' life cycle impact.

The study has been carried out by including the following aspects and phases: sewerage system, construction materials, land use, electricity use, chemical use, the expected lifetime of the treatment system and values of discharged treated wastewater. Since the expected life cycle of the operational phase differs between treatment systems, larger scale construction or renovation work (e.g. change of filter material) has been taken into account.

Within this study, allocation has not been used since wastewater treatment does not have any co-functions. Transport has not been accounted for since it is mainly used during construction work and in system check-ups; the influence is, therefore, marginal. In the construction phase, small appliances, e.g. monitoring devices, have not been included, since their weight of the total construction materials is $<2 \%$. Maintenance work, e.g. grass cutting, cleaning, has also been exempted. CW treatment system does not include sludge treatment for the sludge accumulates in the filter material. According to the construction project of ASTS, a sludge-thickening field has been projected, but at the time of the LCA, the sludge treatment had 


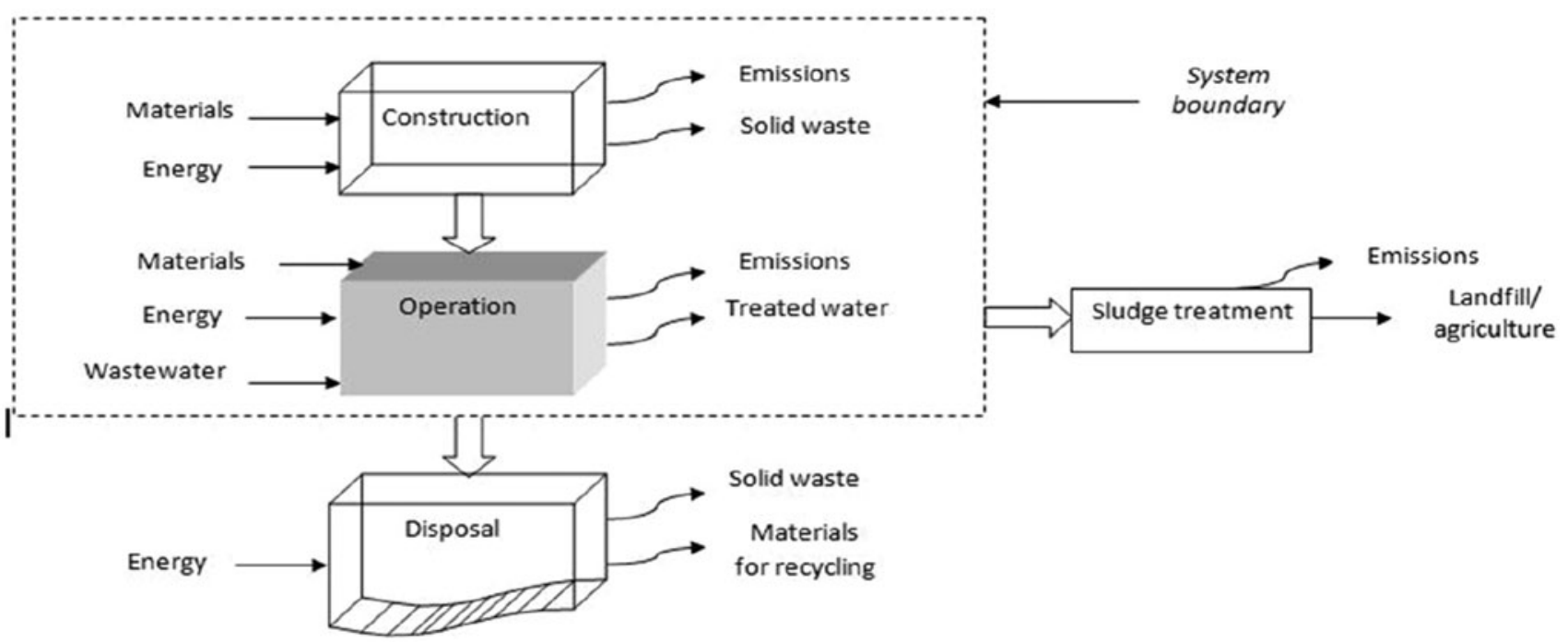

Fig. 3 System boundary of investigated life cycle

Table 1 Life cycle inventory results of constructed wetland without filter material change

\begin{tabular}{|c|c|c|}
\hline Assembly & Material & Quantity \\
\hline \multicolumn{3}{|l|}{ Construction } \\
\hline \multirow[t]{4}{*}{ Sewerage } & Pipe (PVC), kg & 192.04 \\
\hline & Pipe (PE), kg & 22.70 \\
\hline & Well (PP, PE, cast iron), kg & 215.04 \\
\hline & Cable (Al, PVC), kg & 280.00 \\
\hline \multirow[t]{2}{*}{ Mechanical treatment } & Grease trap (glassfiber), $\mathrm{kg}$ & 60.00 \\
\hline & Septic (reinforced concrete, cast iron), $\mathrm{kg}$ & $21,334.58$ \\
\hline \multirow[t]{7}{*}{ Filter } & Geomembrane (EPDM), kg & 833.75 \\
\hline & Geotextile (PP), kg & 82.42 \\
\hline & Pipe (PE), kg & 422.20 \\
\hline & Rubble, kg & $133,000.00$ \\
\hline & LWA, kg & $102,600.00$ \\
\hline & Well (reinforced concrete, steel), $\mathrm{kg}$ & $4,866.20$ \\
\hline & Pump, kg & 28.00 \\
\hline \multicolumn{2}{|c|}{ Use of materials per 1 p.e., $\mathrm{kg}$} & $4,124.01$ \\
\hline \multicolumn{2}{|c|}{ Soil excavation for filter construction per 1 p.e., $\mathrm{kg}$} & $8,575.53$ \\
\hline \multicolumn{3}{|l|}{ Operation } \\
\hline Electricity & For the use of pumping, $\mathrm{kWh} / \mathrm{a}$ & 167.00 \\
\hline \multirow[t]{5}{*}{ Emissions of treated water } & BOD, mg/l & 8.12 \\
\hline & $\mathrm{COD}, \mathrm{mg} / \mathrm{l}$ & 33.00 \\
\hline & $\mathrm{P}$ tot, $\mathrm{mg} / \mathrm{l}$ & 0.54 \\
\hline & $\mathrm{N}$ tot, $\mathrm{mg} / \mathrm{l}$ & 20.37 \\
\hline & Solids tot, mg/l & 6.62 \\
\hline
\end{tabular}

not taken place; therefore, only the construction materials of the sludge-thickening field have been taken into account. This should be qualified as a limitation of ASTS life cycle.

Functional unit has been defined as the treatment of 1 p.e. municipal wastewater, considering a 15-year operating period of the treatment system. According to the legal standards stated by the Estonian authorities, 1 p.e. equals to
$60 \mathrm{~g}$ of BOD per $24 \mathrm{~h}$. This functional unit has used in previous LCAs (Dixon et al. 2003; Hospido et al. 2008; Lundin et al. 2000; Machado et al. 2006; Nogueira et al. 2009) as an alternative to the quantity of inflow water. Since one of the chosen WWTP has a varying yearly water inflow, p.e. as the functional unit was chosen to allow comparisons between systems. 
Table 2 Life cycle inventory results of aerated sludge treatment system

\begin{tabular}{|c|c|c|}
\hline Assembly & Material & Quantity \\
\hline \multicolumn{3}{|l|}{ Construction } \\
\hline \multirow[t]{4}{*}{ Sewerage } & Pipe (PVC), kg & $6,410.68$ \\
\hline & Pipe (PE), kg & 227.61 \\
\hline & Pipe (stainless steel), $\mathrm{kg}$ & 327.36 \\
\hline & Cable (Al, PVC), kg & 140.00 \\
\hline \multirow[t]{4}{*}{ Treatment facilities } & Rubble, kg & $73,948.00$ \\
\hline & Plastic, $\mathrm{kg}$ & 186.35 \\
\hline & Process tank (reinforced concrete), $\mathrm{kg}$ & $462,240.00$ \\
\hline & Cement (portland cement, water, sand), $\mathrm{kg}$ & $1,363.20$ \\
\hline \multirow[t]{6}{*}{ Sludge-thickening field } & Rubble and sand, kg & $141,645.00$ \\
\hline & EPS, $\mathrm{kg}$ & 288.00 \\
\hline & Pipe (PE), kg & 282.59 \\
\hline & Plastic (LDPE), kg & 150.40 \\
\hline & Reinforced concrete, $\mathrm{kg}$ & $134,400.00$ \\
\hline & Mineral wool, $\mathrm{kg}$ & $2,080.00$ \\
\hline \multirow[t]{3}{*}{ Appliances } & Blower and mixer (cast iron, stainless steel), $\mathrm{kg}$ & 346.00 \\
\hline & Diffuser (EPDM, PP), kg & 61.60 \\
\hline & Coagulant container (HDPE), $\mathrm{kg}$ & 36.00 \\
\hline \multicolumn{2}{|c|}{ Use of materials per 1 p.e., $\mathrm{kg}$} & 807.97 \\
\hline \multicolumn{2}{|c|}{ Soil excavation for filter construction per 1 p.e., $\mathrm{kg}$} & $3,537.77$ \\
\hline \multicolumn{3}{|l|}{ Operation } \\
\hline Electricity & For the use of treatment, $\mathrm{kWh} / \mathrm{a}$ & $25,000.00$ \\
\hline \multirow[t]{5}{*}{ Emissions of treated water } & BOD, mg/l & 9.13 \\
\hline & $\mathrm{COD}, \mathrm{mg} / \mathrm{l}$ & 76.13 \\
\hline & $\mathrm{P}$ tot, $\mathrm{mg} / \mathrm{l}$ & 0.59 \\
\hline & $\mathrm{N}$ tot, $\mathrm{mg} / \mathrm{l}$ & 14.74 \\
\hline & Solids tot, $\mathrm{mg} / \mathrm{l}$ & 5.38 \\
\hline
\end{tabular}

\section{Construction and use phase of WWTPs}

The inventory data of used materials during construction phase were collected and calculated from the construction project and budget calculation. The following construction materials used to build hybrid $\mathrm{CW}$ treatment system were considered (Table 1).

For sewerage PVC and PE sewer pipes, sewerage wells with cast iron coverage and PVC covered cables were used. Mechanical treatment phase consisted of a reinforced concrete septic tank and a grease trap made from glass fibre. For the wetland filter, two reinforced concrete separation wells, EPDM, geomembrane, geotextile, PE pipes, different sized LWA and different sized rubble were used. The excavation work for removal of the soil to build the filter was also taken into account. The wastewater was pumped through the system by a low power electrical pump. The functional period of the hybrid wetland treatment system was calculated to be 15 years, including a change of filter materials after 7 years of operation. During the use phase, only electricity is consumed to pump the wastewater, other maintenance work has a minor impact.
The inventory data for ASTS were gained from construction project and constructional drawings; some additional information (like the use of chemicals, maintenance work and use of electricity) was collected from the local municipality and the operator of the WWTP (Table 2).

The sewerage system has been built using PVC, PE and stainless steel pipes and PVC coated cables. The process tank was constructed from reinforced concrete and evened out with Portland cement. For isolation, LDPE sheet and crushed limestone was used. In addition, materials for sludge-thickening field construction have been taken into account.

\section{Results and discussion}

Impact assessment with Impact 2002+ method

The results of the case studies are applicable only if taking into account the limitations and assumptions made during the LCA study. The results of characterisation with Impact $2002+$ method show that in most impact categories, ASTS 
Fig. 4 Comparative characterisation with Impact $2002+$ method where the total impact has been divided between two treatment systems. $C W$ constructed wetland, ASTS extended aeration activated sludge treatment system

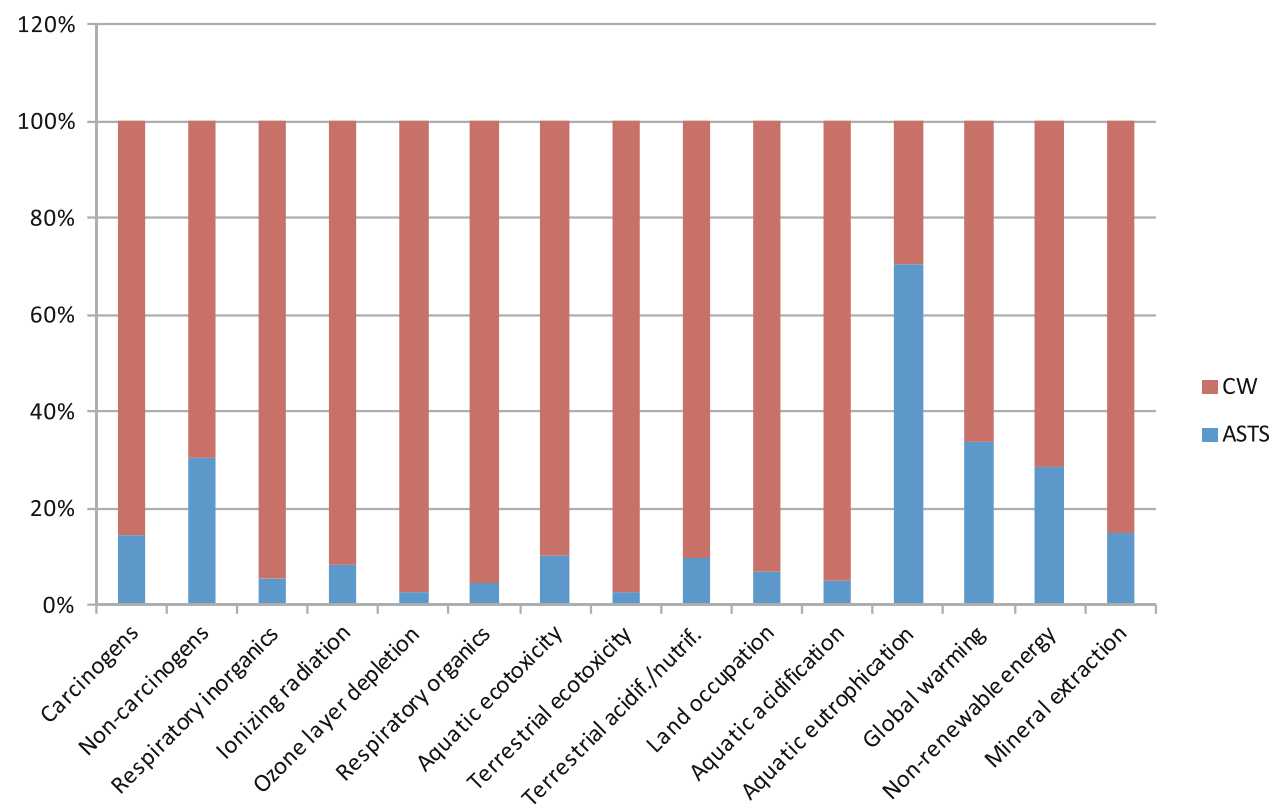

performs better than $\mathrm{CW}$ which on average constitutes $83.64 \%$ of total impact (Fig. 4). The largest influence on the life cycle has the use of LWA in the CW filter which stands out in the following impact categories: human toxicity (carcinogens from aromatic compounds), respiratory effects from organic and inorganic compounds, ionizing radiation, ozone layer depletion, aquatic ecotoxicity, terrestrial acidification/nutrification, aquatic acidification, global warming and the use of non-renewable resources. In non-carcinogenic human toxicity category, the impact is caused by the production of PVC pipes and terrestrial ecotoxicity is influenced by the use of LWA and limestone rubble. Land occupation is affected by the land use to build the treatment system. The biggest influence to mineral extraction impact category is caused by the use of aluminium cables. The only impact category which is dominated by the ASTS is the aquatic eutrophication which is due to the higher concentration of phosphorus compounds in the discharged effluent.

Values from the characterisation phase were normalised using reference values from year 2000, based on the influence of an average European (ILCD Handbook 2010). Eutrophication and acidification impact categories do not have normalisation factors since they are being developed (Jolliet et al. 2003). Most significant impacts were global warming, use of non-renewable energy and respiratory effects from inorganic compounds (Fig. 5). The ASTS amounted $22.65 \%$ of the total impact and CW $77.35 \%$, accordingly. The normalisation results show that the use of crude oil in the production of LWA for the filter and the use of electricity in the activated sludge treatment have the largest impact on the use of non- renewable resources. Inorganic particles $\mathrm{PM}<2.5$ result from the production of LWA. The latter and the use of electricity enlarge the global warming potential. By classifying midpoint categories to endpoint impact categories the most substantial impact according to the normalisation values based on European reference values is on human health in the case of $\mathrm{CW}$ and on resources in the case of ASTS (Fig. 6).

\section{Impact assessment with ReCiPe method}

The assessment with the ReCiPe method shows that the impact of ASTS has slightly enlarged compared to the results gained with Impact $2002+$ with an average impact of $24.91 \%$ by dominating in four impact categories: fresh and marine water eutrophication, freshwater ecotoxicity and water depletion (Fig. 7). The reason lays mainly in the content of nutrients in the effluent. The CW dominates in most of the impact categories with a mean impact of $75.09 \%$. This is also caused mainly by the production and use of LWA. The urban land use is affected by the filter area, and the use of metals influences the metal depletion category. For normalisation, the European reference factors have been used based on the impact caused by an average European in 2006 (this includes all European Union member states as well as Switzerland, Norway and Iceland) (Wegener Sleeswijk et al. 2008). At the time of the research, normalisation factors were available for 17 midpoint categories excluding the use of water resources. The results of assessing the impacts with ReCiPe method indicate that the most significant impact category is the use of natural land when producing LWA, which in addition 
Fig. 5 Midpoint category normalisation with Impact $2002+$ method based on an average European data

Fig. 6 Endpoint category normalisation with Impact $2002+$ method based on an average European data

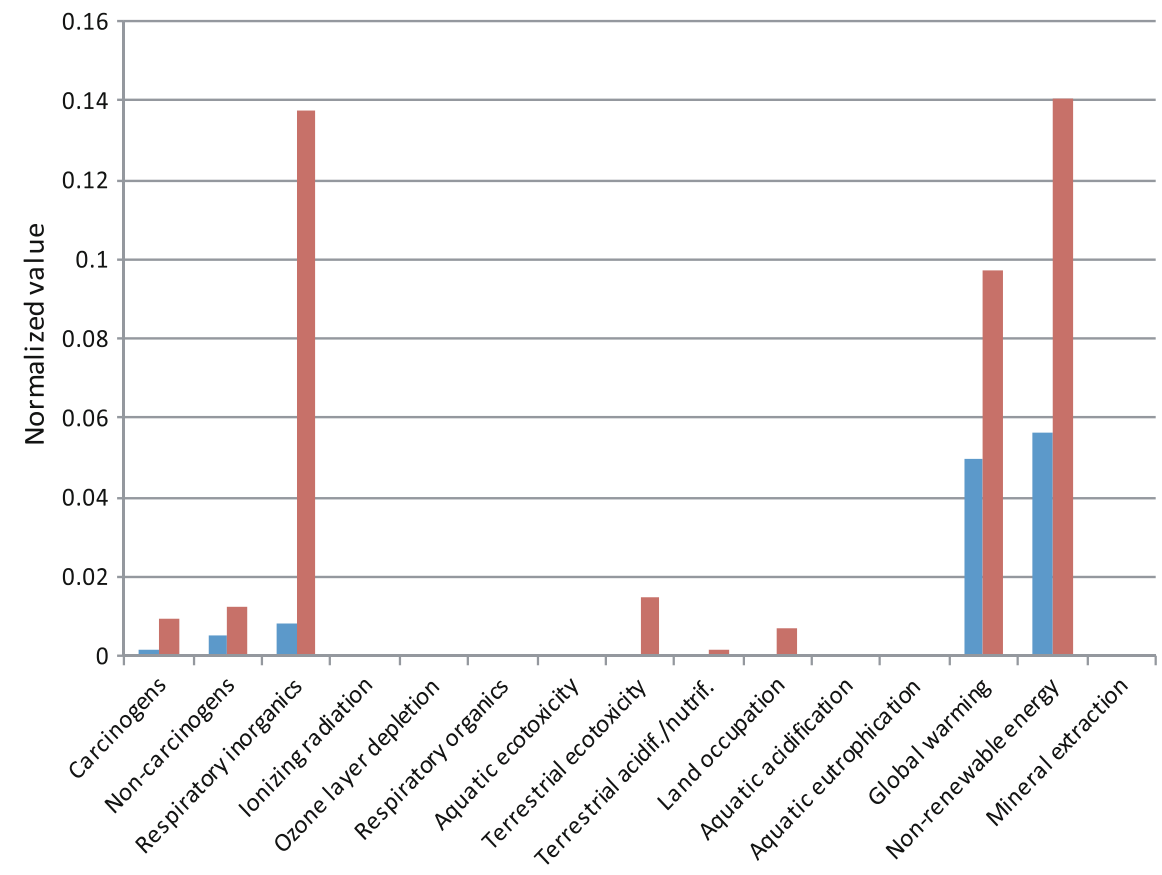

口ASTS

nCW

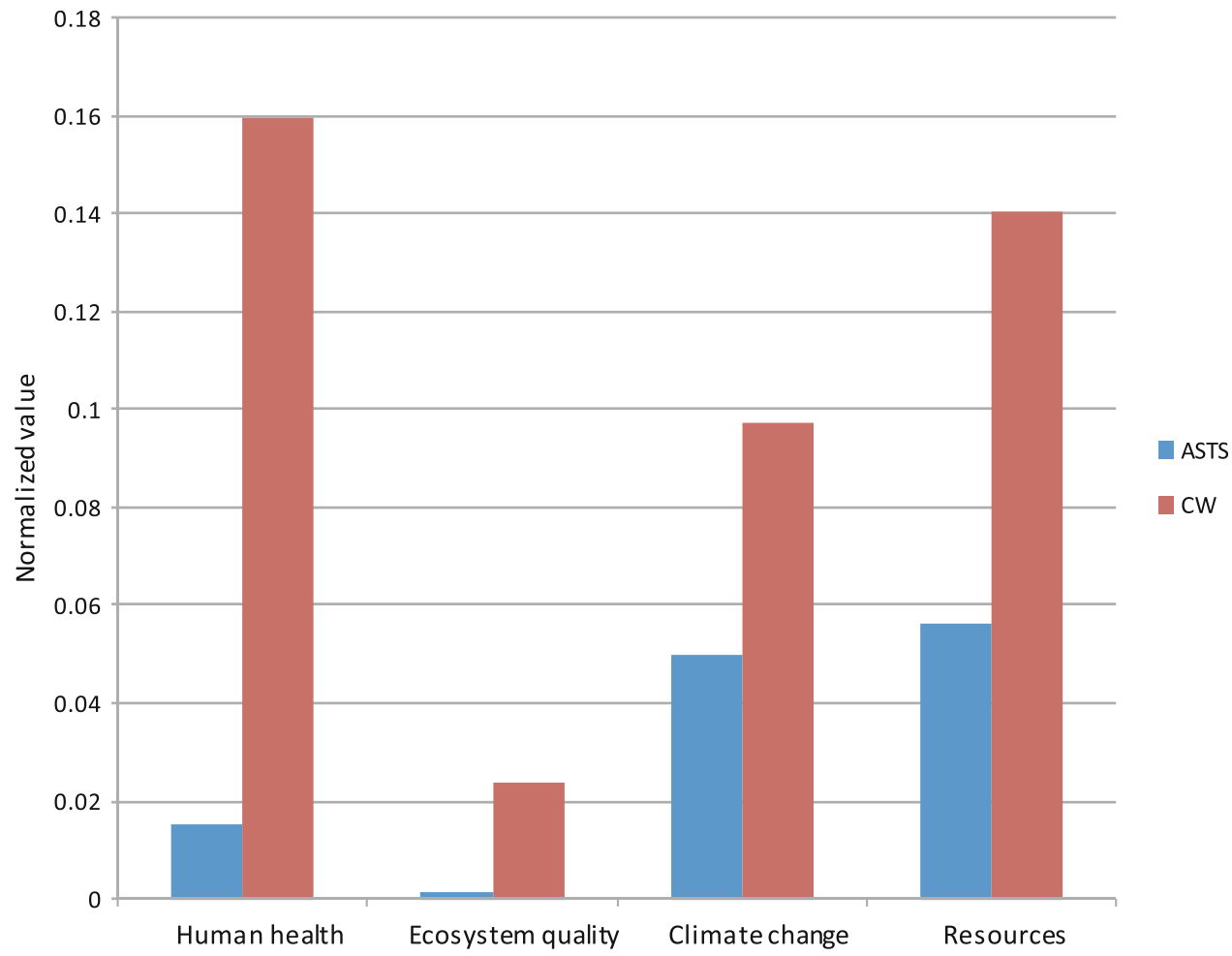

affects also marine ecotoxicity (Fig. 8). The ASTS stands out by contributing to eutrophication and ecotoxicity impact categories. The first category is dependent on the quality of the effluent. Ecotoxicity values are influenced by the landfilling of ash from electricity production which is characteristic to Estonias' electricity production process. When the midpoint categories were divided between damage categories, the use of resources is found dominant in both treatment systems due to the use of crude oil and oil shale (Fig. 9). The CW constitutes about $72 \%$ of the total impact per functional unit. Human health and ecosystems damage categories are dominated by the emissions of $\mathrm{CO}_{2}$ from fossil fuels from the production of LWA and electricity. 
Fig. 7 Comparative characterisation with $\mathrm{ReCiPe}$ method where the total impact has been divided between two treatment systems
Fig. 8 Midpoint category normalisation with ReCiPe method based on an average European data
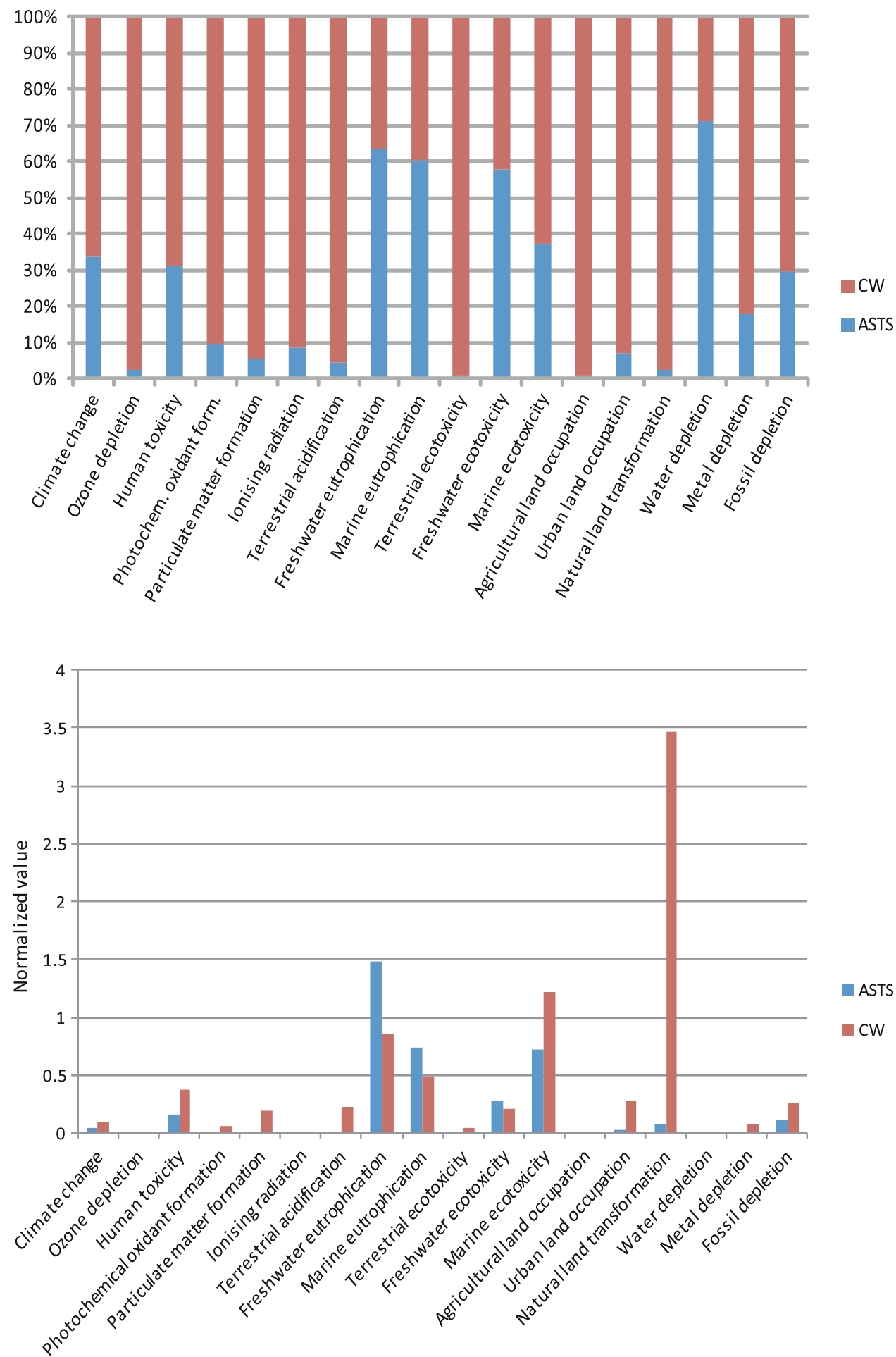

Impacts of construction and use phases of individual WWTP

In order to analyse the results of comparative impact assessment and to determine the phase which influences mostly the performance of a treatment system, an individual impact assessment has to be carried out. The CWs construction phase has been divided into three subcategories: the sewage system, pre-treatment and LWA filter, and the operation phase into two subcategories: the effluent and the use of electricity. The impact assessment has been carried out by taking into account a life cycle of 15 years involving a change of filter material. Characterisation results of the $\mathrm{CW}$ with Impact $2002+$ method show that 
Fig. 9 Damage category normalisation with $\mathrm{ReCiPe}$ method based on an average European data

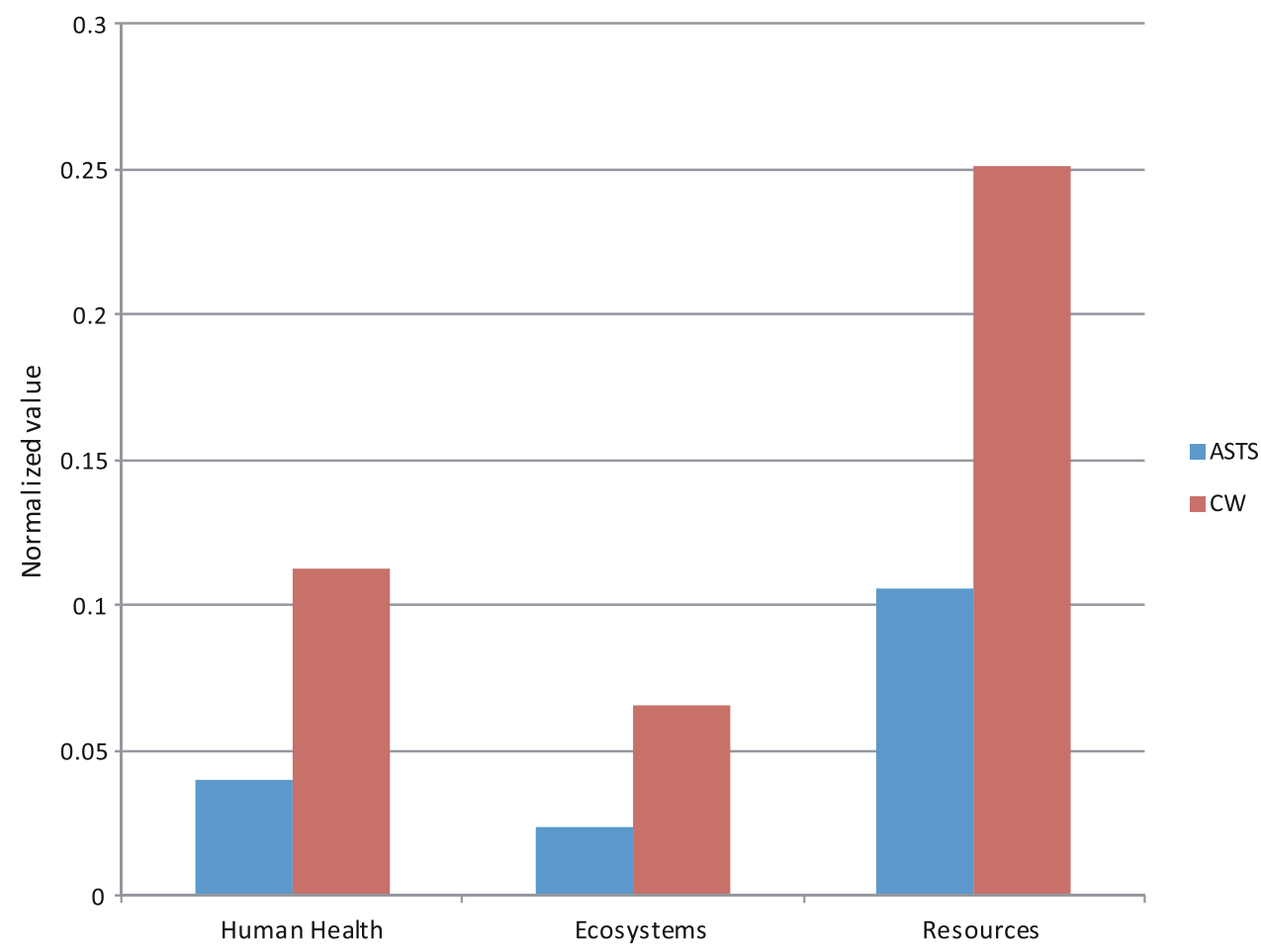

LWA filter has the largest impact with an average of $76.64 \%$ (Fig. 10) followed by sewage system and effluent quality (average impact 11.64 and $5.79 \%$, respectively). Discharged effluent quality influences mostly aquatic eutrophication and sewage system influences human toxicity categories (carcinogens and non-carcinogens) and mineral extraction. Assessment with the ReCiPe method gives close results to Impact 2002+ assessment results with LWA filter having the largest share of impact categories with a mean impact of $73.78 \%$ followed by effluent quality and pre-treatment (average impact 15.01 and $5.68 \%$, respectively).

The ASTS has a longer expected operation phase up to 50 years, which has been taken into account; it involves the change of technical installations, such as pumps after 25 years. The construction phase is subdivided as follows: sewage system outside the treatment system, sewage system within the treatment system, treatment system (process tank), technical installations (appliances), sludge-thickening field and bioponds. The use phase is divided between the effluent quality and the use of electricity. Characterisation with Impact $2002+$ results in higher impacts from the treatment system (average impact $30.76 \%$ of the impact of the total wastewater treatment system) and the use of electricity (average impact $27.28 \%$ ) (Fig. 11). The production of reinforced concrete used to build the process tank prevails in the impact of treatment phase. The use of fossil fuels results in having a large impact on the ASTS use phase. The sewage system outside the treatment system affects human toxicity category, due to the use of plastic pipes. The effluent quality, such as the concentration of nutrients, influences aquatic eutrophication. With the ReCiPe method, the use of electricity is the most dominant impact with a share of $36.18 \%$. The use of electricity causes climate change, human toxicity, photochemical oxidation, aquatic ecotoxicity, terrestrial acidification and fossil fuel depletion. The process tank from the treatment system accounts for $30.25 \%$ of the total impact, influencing ozone depletion, terrestrial ecotoxicity, land use and use of metals.

Contribution and sensitivity analysis

To determine which processes are playing significant role in the results, a contribution analysis was carried out using the SimaPro feature which enables to analyse life cycle processes. It can be performed separately on both treatment systems. In $\mathrm{CW}$ life cycle, the filter has the greatest impact being influenced largely by the use of energy intense LWA and secondly by EPDM membrane. ASTS life cycle is influenced mostly by the use of electricity and to a minor extent by the use of reinforced concrete in the process tank.

In previous research, LCA of CW has been carried out where the filter system was built using only gravel, sand, rubble or splinters, soil, plants or compost (Brix 1999; Dixon et al. 2003; Fuchs et al. 2011; Machado et al. 2006; Memon et al. 2007). This case study differs due to the use 
Fig. 10 Characterisation of CW with Impact 2002+ method based on different life cycle stages

Fig. 11 Characterisation of ASTS with Impact 2002+ method based on different life cycle stages
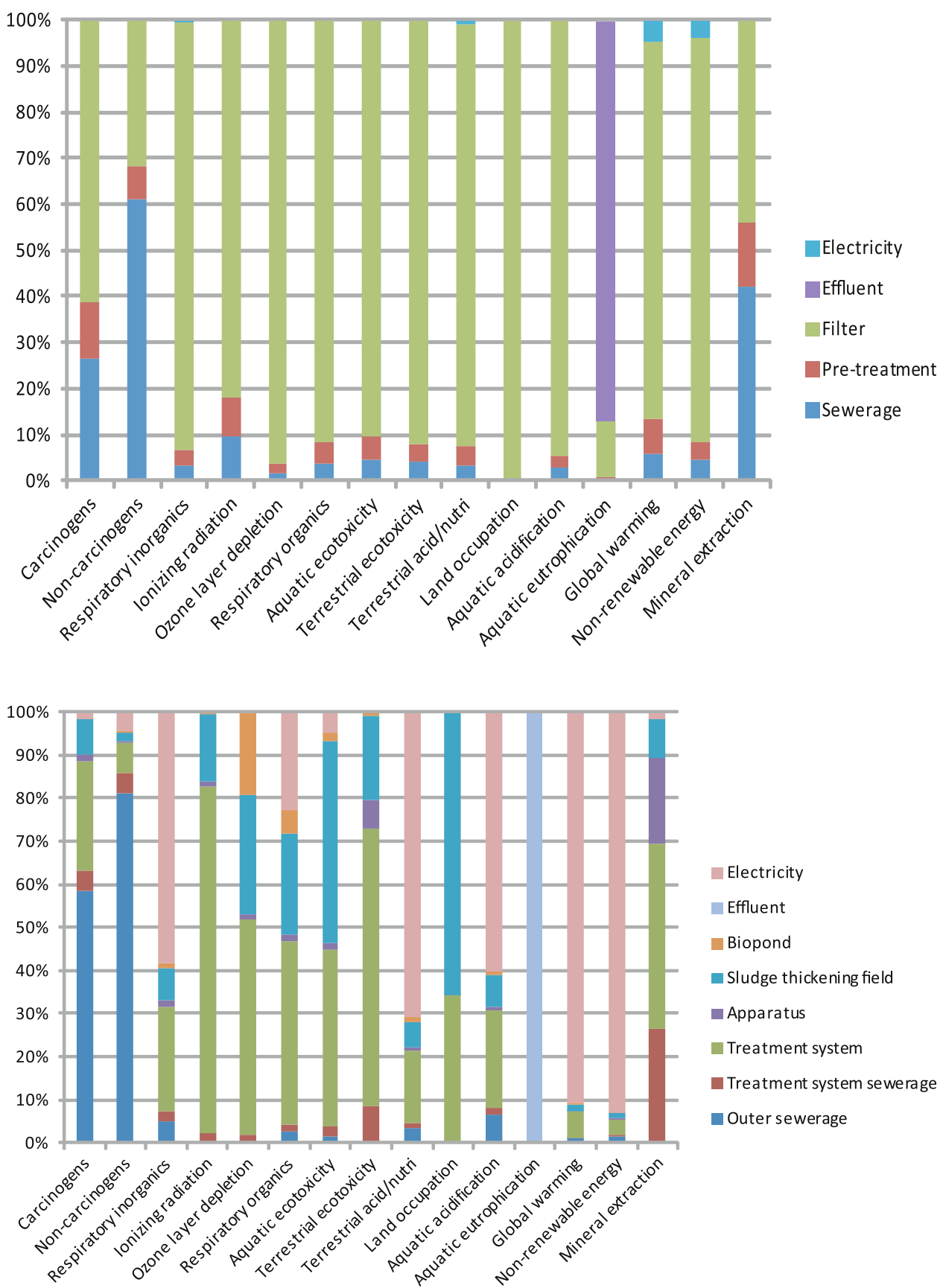

of LWA in the filter. A sensitivity analysis was performed taking into account the assemblies with most significant environmental impacts: LWA as a material in the filter and the use of electricity. To compare the impacts, an alternative scenario was created to substitute LWA for 10:1 sand and gravel filter. This involves only the change in the filter material, and for this study, it is assumed that the effluent quality remains the same. The ReCiPe method was chosen for this impact assessment due to the fact that it takes into account eutrophication and land use which might be important parameters when using sand and gravel.
Characterisation results show that the impact of $\mathrm{CW}$ has decreased with an average of $59 \%$ of the total impact (Fig. 12). The influences of CW are mostly caused by land use and the production of filter materials. Climate change category indicates a negative value which is caused by the uptake of $\mathrm{CO}_{2}$ by the plants used in the hybrid filter. Since not as many fossil fuels are used as with the LWA, this value shows a negative tendency. The ASTS is dominant in categories involving eutrophication due to the effluent quality. After normalisation based on European data, the use of natural land seems to be of more importance than 
Fig. 12 Comparative characterisation of an alternative scenario with ReCiPe method where LWA material in the $\mathrm{CW}$ filter is substituted by sand and gravel
Fig. 13 Comparative damage category normalisation of an alternative scenario with ReCiPe method where LWA material in the CW filter is substituted by sand and gravel
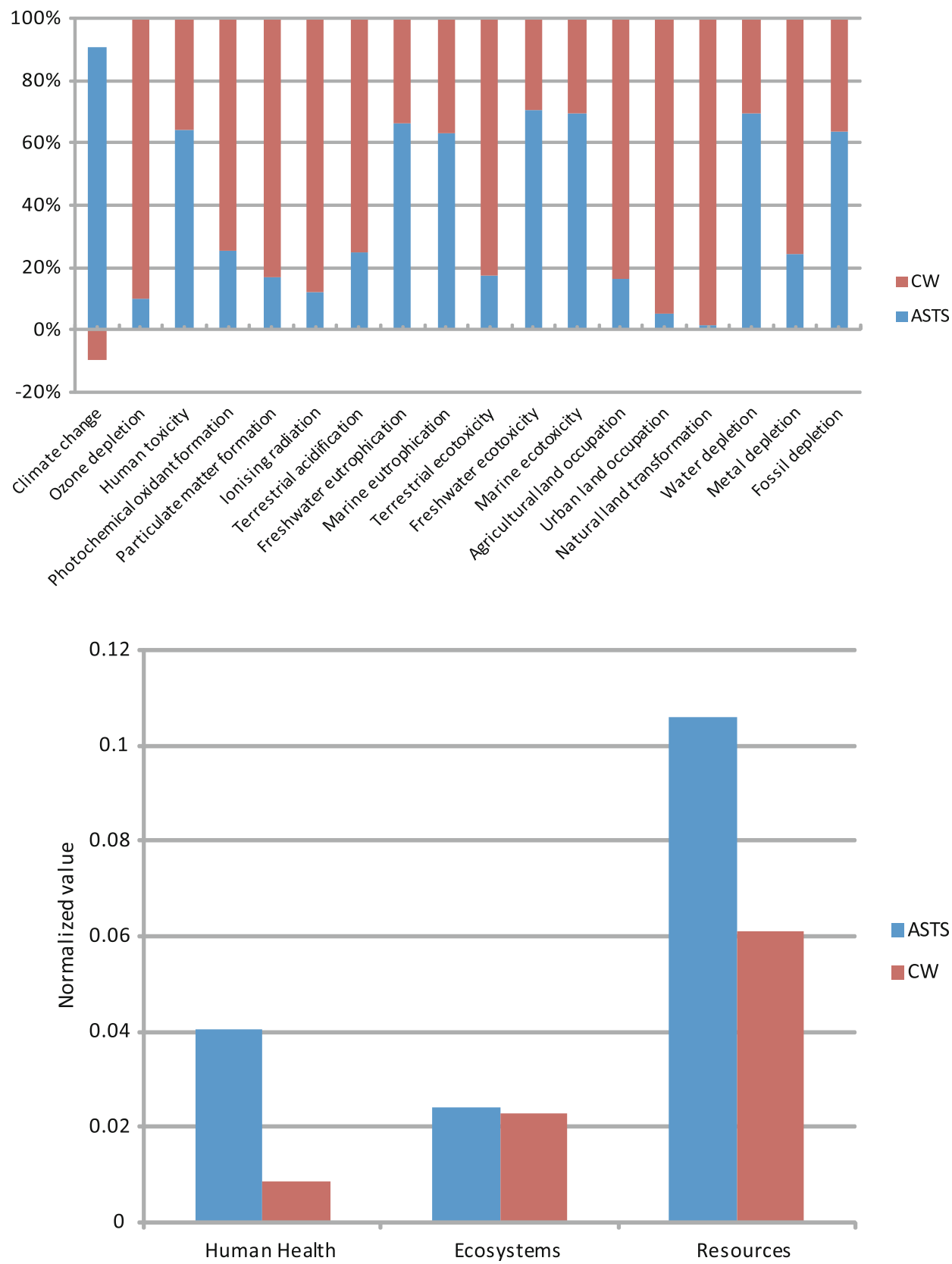

any other category. The $\mathrm{CW}$ in European context has a larger effect on land use due to the fact the available land is scarce in Europe, and therefore, all land intense technologies seem to have a larger effect when taking European data as basis for the assessment. In damage categories the CW outperforms activated sludge treatment (Fig. 13).

Since Estonia produces electricity from oil shale which in the Europe and world context is unique, a comparison with a different energy source was carried out to test the sensitivity of results. By replacing the oil shale electricity use in inventory data with UCTE energy mix from the Ecoinvent database, the ASTS showed an increase in the mean of total impact from 41 to $49 \%$.
When comparing different systems with each other, the assumptions and limitations have to be taken into account when interpreting and using the results as reference. In this study, the CW was characterised by an uneven inflow which was caused by seasonal operation. Generally, $\mathrm{CW}$ treatment systems are technologically less advanced, and therefore, all the construction materials were taken into account whether in the case of ASTS some construction materials had to be left out due to lack of data. The use of electricity was based on calculations, not on measured use. Transport and maintenance work have been left out due to marginal influence on the life cycle as well as sludge treatment which had not been in place by the start of the research. 
Comparative results with Impact $2002+$ method show that $\mathrm{CW}$ dominates in all impact categories, except in aquatic eutrophication category. $\mathrm{CW}$ treatment system has a higher material consumption per 1 p.e., and the main effect is due to the production of LWA but to a lesser extent due to the impact of EPDM, PVC pipes, rubble, electrical cable and land use. Lundin et al. (2000) research confirms that environmental loads from the construction of smaller wastewater systems contribute a lot to the total loads. The comparative results show that ASTS dominance in eutrophication category is due to phosphorus released with the discharge to the environment. According to the water analysis, the mean $\mathrm{P}$ total of ASTS was higher compared to CW discharge values, 0.59 and $0.54 \mathrm{mg} / \mathrm{l}$, respectively. Normalised results show the relative importance of LWA used in CW filter and the use of electricity for operating ASTS. Therefore, the overall environmental impacts can be reduced using less LWA or substituting the material with less energy intensive alternative, in the case of ASTS the electricity should be used sparingly.

When comparing the results between Impact 2002+ method and ReCiPe method, an increase in the proportion of ASTS impacts can be seen with ReCiPe method, partly because there are three categories that are related to the impact of discharged effluent instead of one and because of the impact from electricity production is higher in ReCiPe method. In normalisation phase the ReCiPe method takes into account eutrophication and acidification, and the results show that ASTS is dominating in eutrophication categories. $\mathrm{CW}$ negative impact on the environment is mainly due to the production of LWA.

An alternative scenario for the sensitivity analysis was chosen to compare the studied system with a more conventional option. The results show that by replacing the LWA in the filter with sand and gravel, the environmental impacts were reduced by an average of $15.86 \%$. When normalising characterisation results, the impact of $\mathrm{CW}$ decreased on average by $10.78 \%$. Comparison of both treatment systems when LWA filter material is used shows that $\mathrm{CW}$ has 2-3 times higher environmental load per functional unit depending on the impact assessment method. When replacing filter material with sand and gravel, the characterisation results were 1.5 times higher compared to ASTS. By replacing filter material with a more natural option, it might mean that the effluent quality decreases, therefore, a compromise of the quality of discharged effluent and the environmental load of the used material must be made. Locally produced LWA as a filter material in CWs has shown good hydraulic conductivity and phosphorous sorption capacity; CW with LWA has outstanding purification results and is suitable for conditions with variable hydraulic load and cold winter (Öövel et al. 2007). There is evidence that local sands can only efficiently remove phosphorous for 5-6 years, after which they become saturated (Vohla et al. 2005). Weiss et al. (2008), who assessed the impacts of thermally processed reactive filter materials used in WWTP, concluded that these materials are naturally highly energy consuming and fairly relatively poor in the overall environmental assessment. They concluded as well that the eutrophication values were the lowest for treatment system using reactive filter materials. The findings from the current study are in accordance with the results of Weiss et al. (2008).

Some of the recent LCAs on WWTP have suggested that the use phase has the largest impact on the treatment systems' life cycle (Lassaux et al. 2007; Lundie et al. 2004; Tillman et al. 1998). There have also been LCAs where the construction phase has been exempted based on the need to concentrate only on the performance (Muñoz et al. 2006), or due to the fact that construction phase amounts little if compared to the impact of the whole life cycle (Hospido et al. 2008). Some researchers have concluded that the demolition phase does not have a large impact and is, therefore, left out from the studied system boundary (Dixon et al. 2003; Foley et al. 2007; Machado et al. 2006). According to Larsen and Hauschild (2008), the use of electricity, use of fuels and sludge treatment process increase the impact of the use phase. The results of the current study show that construction phase of CW compared to the use phase has a larger impact on the environment. ASTS characterised results also indicate that construction phase is responsible for the most impacts of wastewater treatment life cycle. Larsen and Hauschild (2008) has noted that although some authors argue that the impact from the construction phase is negligible in the context of the whole life cycle and may be, therefore, excluded from the investigation, it has been found that the construction phase impact may be of importance for certain type of treatment systems (e.g. wetlands, sand filter, conventional active sludge treatment, micro filtration and ozoning). Vlasopoulos et al. (2006) results show that the environmental impact of the construction phase can form $1-96 \%$ of the total impact of the treatment system, depending on the technology and impact assessment methods, especially in the case of CWs. It was assumed when the case studies in question were first analysed the use of electricity will play an important role in the impact of treatment system. The results showed that in the case of ASTS, electricity might have a large impact. Since electricity is being used to produce materials for construction, the influence of the use of electricity might be even greater.

Another assumption was that a technologically less advanced natural type of WWTP would have fewer impacts on the environment when compared to a more complicated and material intense solution. If the filter material used in $\mathrm{CW}$ would be sand and gravel, then the 
environmental impacts when compared with LWA filter material would be reduced by $10-42 \%$ on average depending on the assessment method. The use of plants in the filter system could also help to reduce the impact of global warming by the intake of $\mathrm{CO}_{2}$. Plant development has a significant benefit in the treatment process in the vertical subsurface flow CWs (Cheng et al. 2011). It should be taken into account that when interpreting the results for local conditions, the choice of the WWTP should be based on the overall environmental state, e.g. when an area is especially sensitive to eutrophication, a solution for minimising the content of nutrients in the effluent should be chosen. There should be a compromise between the environmental load of the treatment system itself and the performance of it to comply with environmental standards for the effluent.

One of the aims of the current research was to compare the impact assessment results when using different assessment methods. Most popular methods include EcoIndicator 99, CML 2 baseline, Eco-Points 97, EDIP and EPS2000. ReCiPe or Impact 2002+ methods have been used less in LCAs on WWTPs, which is the reason why these methods in question were chosen. Renou et al. (2008) has pointed out that within each type of method (problem or damage-oriented), the impact categories may be different between methods. Therefore, different impact assessment methods should be used to test the variation of results, although it is not feasible to compare numerical values between methods. The results of the current study indicated that there are variations in the categories and in the importance of categories in the context of normalisation. Testing different assessment methods helps to determine the influence and sensitivity of processes.

LCA provides an opportunity to approach a product or a system in a holistic way and to understand the resulting impacts and their causes. According to Weiss et al. (2008), LCA provides a good basis for making decisions based on holistic approach; it will allow to bring out the weaknesses and aspects of the system that need further investigation and development. Moora (2009) has concluded that LCA as well as other analytical tools are generally a simplification of a complex reality, which is always open to criticism. LCA does not replace the role of a decision maker, but it supports decision making.

\section{Conclusion}

The results show that the main negative impact of $\mathrm{CW}$ is caused by the construction phase and use of expanded clay known as LWA to construct the hybrid filter. Due to the fact that $\mathrm{CW}$ uses little electricity for operation, the impact from the use phase is marginal. Impacts from ASTS are mainly caused from the use of electricity, and effluent quality, therefore use phase has a larger impact. For ASTS, the results are more dependent on the life cycle impact assessment method chosen. The comparison of the two systems being studied was done using a functional unit of treating the wastewater of 1 p.e. during a period of 15 years. The results show that because of the large amount of energy used to produce LWA, the impact of 1 p.e. of $\mathrm{CW}$ is larger than the impact of ASTS. Comparatively, ASTS dominates in categories associated with eutrophication and ecotoxicity. The impact of ASTS on the environment is larger compared to $\mathrm{CW}$ when using ReCiPe method for assessment, this might be due to the fact that it takes into account water resources and eutrophication in a wider scale. As an alternative, it was tested whether a sand and gravel filter would have a smaller impact on the environment. According to the results, a sand and gravel filter would decrease the average impact of $\mathrm{CW}$ by $22.91 \%$. The alternative scenario showed that $\mathrm{CW}$ has a negative value in global warming category, which means that the plant uptake is greater than the emissions from the construction and use phases of the treatment systems. To reduce negative impact on the environment, less energy demanding filter materials should be used for CW system. For ASTS, energy saving solutions should be implemented to reduce the impacts caused by the use of electricity as well as phosphorus removal should be improved. When interpreting impact assessment results, the limitations and the assumptions of the assessment should be taken into account.

Acknowledgments The author would like to acknowledge Prof. Ülo Mander for supervising the research and Prof. Lembit Nei and Siret Talve for guidance and useful comments.

\section{References}

Brix H (1999) How "green" are aquaculture, constructed wetlands and conventional wastewater treatment systems? Water Sci Tech 40(3):45-50

Cheng B, Hu CW, Zhao YJ (2011) Effects of the plant development and pollutant loading on performance of vertical subsurface flow constructed wetlands. Int J Environ Sci Tech 8(1):177-186

Del Broghi A, Gaggero PL, Gallo M, Strazza C (2008) Development of PCR for WWTP based on a case study. Int J LCA 13:512-521

Dixon A, Simon M, Burkitt T (2003) Assessing the environmental impact of two options for smallscale wastewater treatment: comparing a reedbed and an aerated biological filter using a life cycle approach. Ecol Eng 20:297-308

European Commission-Joint Research Centre-Institute for Environment and Sustainability (2010) International Reference Life Cycle Data System (ILCD) Handbook—general guide for life cycle assessment-detailed guidance. Joint Research Centre Web. http://lct.jrc.ec.europa.eu

Foley J, de Haas D, Hartley K, Lant P (2007) Life cycle assessment of biological nutrient removal wastewater treatment plants. In: 
LCM, 3rd International Conference on Life Cycle Management, Zurich, 27-29 Aug 2007

Fuchs VJ, Mihelcic JR, Gierke JS (2011) Life cycle assessment of vertical and horizontal flow constructed wetland for wastewater treatment considering nitrogen and carbon greenhouse gas emissions. Water Res 45:2073-2081

Gallego A, Hospido A, Moreira MT, Feijoo G (2008) Environmental performance of wastewater treatment plants for small populations. Resour Conserv Recycl 52:931-940

Hospido A, Moreira MA, Feijoo G (2008) A comparison of municipal wastewater treatment plants for big centres of population in Galicia (Spain). Int J LCA 13(1):57-64

ISO 14040 (2006) Environmental management-life cycle assessment-principles and framework. International Standardization Organization, Geneva

Jolliet O, Margni M, Charles R, Humbert S, Payet J, Rebitzer G, Rosenbaum R (2003) IMPACT 2002+: a new life cycle impact assessment methodology. Int J LCA 8(6):324-330

Larsen HF, Hauschild M (2008). Review of existing LCA studies on wastewater treatment technologies. In: SETAC-Europe annual meeting, $18^{\text {th }}$, Warsaw, 25-29 May. SETAC Europe, Brussels

Larsen HF, Wenzel H, Hauschild M (2007) New methodology in life cycle impact assessment (LCIA) of waste water treatment. In: MICROPOL \& ECOHAZARD, 5th. Hazardous Substances in Water. Frankfurt/Main, 17-20 June 2007. IWA Specialised Conference on Assessment and Control of Micropollutants

Lassaux S, Renzoni R, Germain A (2007) Life cycle assessment of water from the pumping station to the wastewater treatment plant. Int J LCA 12(2):118-126

Lillenberg M, Yurchenko S, Kipper K, Herodes K, Pihl V, Lõhmus R, Ivask M, Kuu A, Kutti S, Litvin SV, Nei L (2010) Presence of fluoroquinolones and sulfonamides in urban sewage sludge and their degradation as a result of composting. Int J Environ Sci Tech 7(2):307-312

EWC Ltd (2002) Eestis kuni 2000 i.e suuruste reostusallikate reovee (sademe-, olme- ja tootmisvee) puhastustehnoloogiate ja reoveesette käitlemise soovitusliku juhendmaterjali koostamine parima võimaliku tehnika tunnuste määramiseks, 174. Estonian Environmental Ministry Web. http://www.envir.ee/orb.aw/class= file/action=preview/id=1084459/Alla $+2000+$ ie + puhastid.pdf

Lundie S, Peters GM, Beavis PC (2004) Life cycle assessment for sustainable metropolitan water systems planning. Environ Sci Technol 38:3465-3473

Lundin M, Bengtsson M, Molander S (2000) Life cycle assessment of wastewater systems: influence of system boundaries and scale on calculated environmental loads. Environ Sci Technol 34:180-186

Machado AP, Urbano L, Brito A, Janknecht P, Rodriquez JJ, Nogueira R (2006) Life cycle assessment of wastewater treatment options for small and decentralized communities: energy-saving systems versus activated sludge. In: IWA, 10th. International Conference on Wetland Systems for Water Pollution Control. Lisbon, 23-29 Sept 2006. International Water Association, London

Malakootian M, Nouri J, Hossaini H (2009) Removal of heavy metals from paint industries wastewater using Leca as an available adsorbent. Int J Environ Sci Tech 6(2):183-190
Memon FA, Zheng Z, Butler D, Shirley-Smith C, Lui S, Makropoulos C, Avery L (2007) Life cycle impact assessment of greywater recycling technologies for new developments. Environ Monit Assess 129:27-35

Moora H (2009) Life cycle assessment as a decision support tool for system optimisation-the case of waste management in Estonia. $\mathrm{PhD}$ Dissertation, Tallinn University of Technology, Tallinn

Muñoz I, Peral J, Ayllón JA, Malato S, Passarinho P, Domènech X (2006) Life cycle assessment of a coupled solar photocatalyticbiological process for wastewater treatment. Water Res 40:3533-3540

Nogueira R, Brito AG, Machado AP, Salas JJ, Vera L, Martel G (2009) Economic and environmental assessment of small and decentralized wastewater treatment systems, Desalin. Water Treat 4(1-3):16-21

Öövel M, Tooming A, Mauring T, Mander Ü (2007) Schoolhouse wastewater purification in a LWA-filled hybrid constructed wetland in Estonia. Ecol Eng 29:17-26

Renou S, Thomas JS, Aoustin E, Pons MN (2008) Influence of Impact assessment methods in wastewater treatment LCA. J Clean Prod 16:1098-1105

Roeleveld PJ, Klapwijk A, Eggels PG, Rulkens WH, van Starkenburg W (1997) Sustainability of municipal wastewater treatment. Water Sci Technol 35(10):221-228

Sabanov S, Pastarus JR, Nikitin O (2006) Environmental impact assessment of Estonian oil shale mining systems. In: International Oil Shale Conference: on recent trends in oil shale, Amman, 7-9 Nov 2006. Sustainable Development Network Programme, Jordan

Stewart JR, Collins MW, Anderson R, Murphy WR (1999) Life cycle assessment as a tool for environmental management. Clean Technol Environ Policy 1:73-81

Tangsubkul N, Beavis P, Moore SJ, Lundie S, Waite TD (2005) Life cycle assessment of water recycling technology. Water Resour Manage 19:521-537

Tillman A-M, Svingby M, Lundström H (1998) Life cycle assessment of municipal waste water systems. Int J LCA 3(3):145-157

Tooming A (2005) Performance analysis of a LWA-filled hybrid constructed wetland for wastewater treatment: a case study from Paistu School, Estonia. MSc thesis, University of Tartu, Tartu

Vlasopoulos N, Memon FA, Butler D, Murphy R (2006) Life cycle assessment of wastewater treatment technologies treating petroleum process waters. Sci Total Environ 367:58-70

Vohla C, Põldvere E, Noorvee A, Kuusemets V, Mander Ü (2005) Alternative filter media for phosphorous removal in a horizontal subsurface flow constructed wetland. J Environ Sci Heal Part A 40(6-7):1251-1264

Wegener Sleeswijk A, van Oers LFCM, Guinée JB, Strujs J, Huijbregts MAJ (2008) Normalisation in product life cycle assessment: an LCA of the global and European economic systems in the year 2000. Sci Total Environ 390:227-240

Weiss P, Eveborn D, Kärrman E, Gustafsson JP (2008) Environmental systems analysis of four on-site wastewater treatment options. Resour Conserv Recycl 52:1153-1161 